\title{
Development and characterization of 16 novel microsatellite markers by Transcriptome sequencing for Angelica dahurica and test for cross-species amplification
}

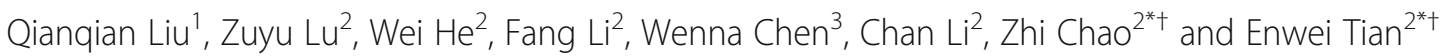

\begin{abstract}
Background: Angelica dahurica (Apiaceae) is an important herb in traditional Chinese medicine. Because of its important medicinal and economic values, its wild resources were over-exploited and increasingly reduced. Meanwhile, the diversity of cultivars of $A$. dahurica has decreased as a result of long-term artificial cultivation. However, there are no population genetics studies of natural A. dahurica reported yet, especially for using microsatellite markers (SSRS) to investigate population genetics of the species.
\end{abstract}

Results: Sixteen polymorphic EST-SSR loci were isolated from A. dahurica with transcriptome sequencing technology (RNA-Seq). The number of alleles varied from 2 to 15 per polymorphic locus over populations with the observed and expected heterozygosities ranging from 0.000 to 1.000 and from 0.000 to 0.829 , respectively. Significant deviations from Hardy-Weinberg equilibrium were observed at 8 loci. Tests of linkage disequilibrium showed 11 informative locus pairs were significant across all populations. Cross-species amplification showed that 14 out of 16 SSR loci have the transferability in cultivar-A. dahurica Cv. 'Hangbaizhi' and A. decursiva.

Conclusions: The 16 newly developed loci microsatellite primers with RNA-Seq will be useful for further investigating population genetics of $A$. dahurica, cultivars and other members of this genus.

Keywords: SSR markers, RNA-Seq, Angelica dahurica, Population genetics, Genetic diversity

\section{Background}

Angelica dahurica (Hoffm.) Benth. et Hook. f. ex Franch. \& Sav., is an important medicinal plant, whose roots (Angelicae Dahuricae Radix) have been used as the important traditional Chinese medicine "bai zhi" for thousands of years [1]. A. dahurica is widely cultivated in North China, who has two cultivars, namely $A$. dahurica

\footnotetext{
*Correspondence: chaozhi@smu.edu.cn; tianenwei@126.com

${ }^{\dagger}$ Zhi Chao and Enwei Tian contributed equally to this work.

${ }^{2}$ School of Traditional Chinese Medicine, Southern Medical University, Guangzhou 515005, China

Full list of author information is available at the end of the article
}

cv. 'Hangbaizhi' and A. dahurica cv. 'Qibaizhi'. These herbs are thought to have the efficacies of eliminating wind-cold and dampness, expelling pus and relieving pain [2]. In addition to its medicinal uses, A. dahurica and its cultivars are also used as raw materials of cosmetics and flavorant [3]. Due to the medicinal and economic values, wild resources of $A$. dahurica were increasingly reduced by over-exploitation and habitat destruction. Meanwhile, the two cultivars of $A$. dahurica have gone through a long time artificial selection, resulting in the decline of the genetic diversity and disease

C C The Author(s). 2020 Open Access This article is licensed under a Creative Commons Attribution 4.0 International License, which permits use, sharing, adaptation, distribution and reproduction in any medium or format, as long as you give appropriate credit to the original author(s) and the source, provide a link to the Creative Commons licence, and indicate if changes were made. The images or other third party material in this article are included in the article's Creative Commons licence, unless indicated otherwise in a credit line to the material. If material is not included in the article's Creative Commons licence and your intended use is not permitted by statutory regulation or exceeds the permitted use, you will need to obtain permission directly from the copyright holder. To view a copy of this licence, visit http://creativecommons.org/licenses/by/4.0/ The Creative Commons Public Domain Dedication waiver (http://creativecommons.org/publicdomain/zero/1.0/) applies to the data made available in this article, unless otherwise stated in a credit line to the data. 
and insect resistance $[4,5]$. Gene flow between two cultivars from different producing areas might lead to out-breeding depression, and then, the depressed gene flow goes into the adjacent natural populations of $A$. dahurica which might cause its decline in the adaptability to local environment [6]. Wild resources usually have high genetic variation and are valuable germplasm. One of the keys to biodiversity conservation is to protect species, more specifically, to protect the genetic diversity or evolutionary potentials of species. Therefore, in order to ensure the sustainable utilization of Angelica dahurica resources, conservation genetics research should be strengthened to protect the genetic diversity of this species as much as possible. The assessment of genetic diversity and population genetic structure in A. dahruica could help to formulate scientific and effective protection strategies.

Microsatellite markers are simple sequences repeat (SSRs) consisting of 1-6 nucleotides in length (motifs) and can be found in genomes of all prokaryotes and eukaryotes [7]. During the past decades, microsatellite markers, due to the high level of polymorphism, high abundance, co-dominance, selective neutrality and transferability across species [8-12], have been widely applied to a variety of biological researches, such as population genetics, gene flow, phylogenetics, and conservation genetics. A latest study has reported 18 polymorphic loci isolated from Angelica sinensis [13]. However, no microsatellite loci were successfully applied to $A$. dahurica, which might have resulted from low success rate of amplification or no polymorphism. Therefore, it is necessary to develop novel microsatellite makers to conduct the population genetics on $A$. dahurica.

Next-generation sequencing technology is a powerful, cost-effective, and reliable tool, generating a large number of sequence data, which can assist us to develop SSR markers [14-17]. Especially, RNA-Seq with Illumina sequencing can help researchers in the identification and development of a large number of SSR markers, which is faster, easier, and more cost-effective compared to traditional SSR development processes [18]. This study aims to use the RNA-Seq technology to develop novel microsatellite markers which would be useful in evaluating the genetic diversity and population structure of $A$. dahurica. We also hope to use the novel SSR markers as an effective tool for further study on conservations of $A$. dahruica.

\section{Results}

\section{Assessment of the quality and quantity of RNA/DNA}

The concentration and purity $\left(\mathrm{OD}_{260 / 280}\right)$ of extracted RNA from the sample (Voucher no. 2017826-CD-X) was $256.7 \mathrm{ng} / \mathrm{ul}$ and 2.02 , respectively, which were satisfied for the requirement of Illumina sequencing. DNA extracted from 89 individuals of four populations were also qualified, whose concentration and purity $\left(\mathrm{OD}_{260 / 280}\right)$ ranged from $38.6 \mathrm{ng} / \mathrm{ul}$ to $398.3 \mathrm{ng} / \mathrm{ul}$ and from 1.64 to 1.99 , respectively.

\section{SSR markers screening and polymorphisms assessment}

In total, RNA-Seq yielded 85,000,882 clean paired-end reads at least $150 \mathrm{bp}$ in length, and 85,650 unigenes were gained from the clean reads performed by de novo assembly with Trinity. MISA totally identified 11,289 putative SSRs. According to this detailed information, 9436 (83.6\%) primer pairs were designed with the program Primer3 and assessed loci containing di-, tri-, tetra-, penta-, and hexanucleotide repeat motifs. Thirty loci were randomly selected to amplify 5 samples from each of the four populations. However, 14 out of the 30 loci failed to amplify the test samples or performed nonspecific amplification. The remaining 16 loci (Table 1) could amplify and yielded polymorphic amplification products in the four populations (Table 2, Additional file: Table S1).

The number of alleles ranged from 2 to 15 per polymorphic locus over the four populations (Table 2) while observed and expected heterozygosities ranged from 0.000 to 1.000 , with average 0.512 and from 0.000 to 0.829 , with average 0.488 , respectively. Significant deviations from HWE were observed at 8 loci (Table 2). Deviation from HWE likely resulted in null alleles, which were detected in $68.8 \%$ of these loci, according to the Micro-Checker analyses. Tests of linkage disequilibrium were significant for 11 pairs of loci across all populations (AD9 and AD10, AD9 and AD8, AD9 and AD17, AD9 and $\mathrm{AD} 11, \mathrm{AD} 11$ and $\mathrm{AD} 19, \mathrm{AD} 2$ and $\mathrm{AD} 4, \mathrm{AD} 7$ and $\mathrm{AD} 14, \mathrm{AD} 8$ and $\mathrm{AD} 11, \mathrm{AD} 10$ and $\mathrm{AD} 11, \mathrm{AD} 1$ and AD11, AD23 and AD24 $(P<0.01)$. After sequential Bonferroni correction, none of the informative locus pairs at BX、AS、CD population was significant while at KS population, five pairs were significant (AD8/AD9; AD10/AD9; AD11/AD9; AD17/AD9; AD11/AD19). These results indicate that the newly developed microsatellite primers will be useful for further investigating population genetics of $A$. dahurica and other members of this genus.

\section{Cross-species amplification}

The 16 polymorphic SSR loci isolated from A. dahurica were tested for amplification in 10 individuals of Angelica dahurica cv. 'Hangbaizhi' and 5 individuals of Angelica decursiva. The results showed that 14 of the 16 SSR loci (87.5\%) had transferability in both $A$. dahurica cv. 'Hangbaizhi' and $A$. decursiva, respectively (Table 3 ). 
Table 1 Characteristics of 16 microsatellite primers developed for Angelica dahurica

\begin{tabular}{|c|c|c|c|c|c|}
\hline Locus & Forward and reverse primer sequences & Motifs & product Size range (bp) & $T_{a}$ & GenBank Accession No \\
\hline AD1 & F:TCCTCCAGCTGGCATAATAATAA R:ATTAAAAAGAACAAGGGGCTCAA & (TGC)6 & $111-123$ & 55 & MH220032 \\
\hline AD2 & F:CTITTTCCCCAATTCCTATCAAC R:CACACCCGTAGAGATACACACTG & $(\mathrm{TA}) 9$ & $136-188$ & 55 & MH220033 \\
\hline AD4 & $\begin{array}{l}\text { F:TTAACAACTGGCTTTGATCCATT } \\
\text { R:TGGAGGTTTGTACGATTTTATGG }\end{array}$ & $(\mathrm{TG}) 9$ & $90-126$ & 50 & MH220034 \\
\hline AD7 & $\begin{array}{l}\text { F:GCTCTCTTAAATTTCACCCCAAC } \\
\text { R:TACTAGATTCTTCCAGAGCGACG }\end{array}$ & (ATTACC) 4 & $131-155$ & 55 & MH220035 \\
\hline AD8 & $\begin{array}{l}\text { F:TTCAACATGGTCATGTGAGTGAT } \\
\text { R:CCGTTGGAGGTCTTCTTGTAAAT }\end{array}$ & $($ GGAGTG)4 & $140-164$ & 53 & MH220036 \\
\hline AD9 & F:CAACACACATGATCCAGAAGAAA R:GAGCTGGAGATAGTCTGTTGCAT & $(\mathrm{TCTGCA}) 10$ & $99-159$ & 50 & MH220037 \\
\hline AD10 & $\begin{array}{l}\text { F:AGACTGCACCTGTCTCATTITC } \\
\text { R:GGCTTGTAATTAATCTTTGCACC }\end{array}$ & $(\mathrm{GT}) 9$ & $116-140$ & 50 & MH220038 \\
\hline AD11 & $\begin{array}{l}\text { F:TTCGTCATTTAGAAACGATAGCA } \\
\text { R:TCAATGGATACCACCACATCATA }\end{array}$ & $(\mathrm{TCT}) 7$ & $127-142$ & 50 & MH220039 \\
\hline AD12 & $\begin{array}{l}\text { F:AAGTTCAATATTCCCCTGGTGAC } \\
\text { R:GTACATTATACCCTCCCCAAACC }\end{array}$ & (AAACC) 4 & $126-131$ & 55 & MH220040 \\
\hline AD14 & $\begin{array}{l}\text { F:TGTACTCCATGGACTGGAGTCTT } \\
\text { R:TTTGTTTCTGACAAAGCCAAAT }\end{array}$ & $(\mathrm{TCA}) 7$ & $108-123$ & 50 & MH220041 \\
\hline AD17 & $\begin{array}{l}\text { F:GGATCATGTTGATGATGGAAAAT } \\
\text { R:TTCGATAACTACAGCAGATGAGC }\end{array}$ & $(A G A) 7$ & $145-163$ & 50 & MH220042 \\
\hline AD19 & $\begin{array}{l}\text { F:CCCCATTTCTCCCATAGATAGAT } \\
\text { R:CCATTAATTGTTCTGCATTTCC }\end{array}$ & $(G C A) 6$ & $125-140$ & 53 & MH220043 \\
\hline AD22 & F: AAACAATATCAAATCAAATGGCGR: GTGGTGATGATGAATCTTGTGAA & $(\mathrm{TTC}) 6$ & $84-99$ & 50 & MH844986 \\
\hline AD23 & F: GCTTGACATATATCATCGCCTITR:TAGACCAAGAGCCAAATAAACCA & $(\mathrm{CTT})_{6}$ & $130-142$ & 50 & MH844987 \\
\hline AD24 & F: GCGAGATGGAAATGACAAATTCTR: ATCCCACCATTTCCTCATTAAGT & $(G C A)_{6}$ & $108-117$ & 50 & MH844988 \\
\hline AD26 & F: ACAAACAAACCAAATCAATCTCGR: TTATCTTCCAATTGCTTGTTGCT & $(\mathrm{CAAAC}) 4$ & $118-123$ & 50 & MH844989 \\
\hline
\end{tabular}

Table 2 Genetic diversity parameters obtained with 16 microsatellite loci across four populations of Angelica dahurica

\begin{tabular}{|c|c|c|c|c|c|c|c|c|c|c|c|c|}
\hline \multirow[b]{2}{*}{ Locus } & \multirow[b]{2}{*}{$\mathrm{Na}{ }^{\mathrm{b}}$} & \multirow{2}{*}{$\begin{array}{l}\mathrm{BX} \operatorname{pop}\left(\mathrm{N}^{\mathbf{a}}=24\right) \\
\mathrm{H}^{c}\end{array}$} & \multirow[b]{2}{*}{$H \mathrm{e}^{\mathrm{d}}$} & \multirow[b]{2}{*}{$\mathrm{Na}$} & \multicolumn{2}{|c|}{ AS pop $(\boldsymbol{N}=17)$} & \multirow[b]{2}{*}{$\mathrm{Na}$} & \multicolumn{2}{|c|}{$\mathrm{KS} \operatorname{pop}(\boldsymbol{N}=24)$} & \multirow[b]{2}{*}{$\mathrm{Na}$} & \multicolumn{2}{|c|}{$C D \operatorname{pop}(N=24)$} \\
\hline & & & & & $\overline{H o}$ & $\mathrm{He}$ & & $\overline{H o}$ & $\mathrm{He}$ & & $\overline{H o}$ & $\mathrm{He}$ \\
\hline $\mathrm{AD}^{*}$ & 9.00 & 0.667 & 0.747 & 9.00 & 0.733 & 0.829 & 4.00 & 0.435 & 0.504 & 8.00 & 0.522 & 0.768 \\
\hline AD10* & 7.00 & 1.000 & 0.712 & 7.00 & 1.000 & 0.785 & 4.00 & 0.917 & 0.687 & 7.00 & 0.870 & 0.684 \\
\hline AD8 & 5.00 & 0.667 & 0.541 & 4.00 & 0.294 & 0.263 & 3.00 & 0.333 & 0.603 & 4.00 & 0.478 & 0.398 \\
\hline AD7 & 3.00 & 0.417 & 452 & 3.00 & 0.412 & 0.403 & 2.00 & 0.250 & 0.219 & 1.00 & 0.000 & 0.000 \\
\hline AD9* & 7.00 & 0.750 & 0.743 & 3.00 & 0.353 & 0.552 & 5.00 & 0.542 & 0.685 & 8.00 & 0.667 & 0.600 \\
\hline AD1 & 4.00 & 0.417 & 0.506 & 4.00 & 0.294 & 0.306 & 3.00 & 0.417 & 0.338 & 2.00 & 0.167 & 0.153 \\
\hline $\mathrm{AD} 17^{*}$ & 5.00 & 0.667 & 0.739 & 4.00 & 0.765 & 0.657 & 3.00 & 0.625 & 0.633 & 4.00 & 0.625 & 0.563 \\
\hline $\mathrm{AD} 14^{*}$ & 5.00 & 0.917 & 0.576 & 5.00 & 0.882 & 0.619 & 4.00 & 0.917 & 0.608 & 2.00 & 0.000 & 0.080 \\
\hline $\mathrm{AD} 4^{*}$ & 6.00 & 0.917 & 0.731 & 4.00 & 0.765 & 0.673 & 5.00 & 0.208 & 0.594 & 3.00 & 0.042 & 0.155 \\
\hline AD11 & 4.00 & 0.667 & 0.595 & 3.00 & 0.588 & 0.552 & 4.00 & 0.583 & 0.688 & 3.00 & 0.500 & 0.531 \\
\hline AD12 & 2.00 & 0.458 & 0.499 & 2.00 & 0.353 & 0.457 & 2.00 & 0.304 & 0.258 & 2.00 & 0.348 & 0.287 \\
\hline AD19 & 5.00 & 0.583 & 0.611 & 4.00 & 0.706 & 0.734 & 3.00 & 0.583 & 0.569 & 4.00 & 0.625 & 0.526 \\
\hline AD22 & 5.00 & 0.375 & 0.389 & 4.00 & 0.765 & 0.512 & 5.00 & 0.792 & 0.576 & 6.00 & 0.750 & 0.621 \\
\hline AD23* & 1.00 & 0.000 & 0.000 & 2.00 & 0.400 & 0.444 & 2.00 & 0.087 & 0.287 & 3.00 & 0.042 & 0.155 \\
\hline AD24* & 4.00 & 0.421 & 0.580 & 3.00 & 0.615 & 0.521 & 4.00 & 0.652 & 0.509 & 3.00 & 0.833 & 0.531 \\
\hline AD26 & 2.00 & 0.304 & 0.258 & 2.00 & 0.059 & 0.057 & 2.00 & 0.458 & 0.353 & 1.00 & 0.000 & 0.000 \\
\hline Average & 4.63 & 0.577 & 0.543 & 3.94 & 0.562 & 0.523 & 3.44 & 0.506 & 0.507 & 3.81 & 0.404 & 0.378 \\
\hline
\end{tabular}


Table 3 Cross-amplification results for the 16 SSR loci developed from Angelica dahurica in Angelica dahurica cv 'Hangbaizi' and congeneric Angelica decursiva

\begin{tabular}{llll}
\hline & & Size ranges & \\
\hline Locus & $\begin{array}{l}\text { Angelica dahurica 'Hangbaizhi' } \\
\text { (NZ pop) }\end{array}$ & $\begin{array}{l}\text { Angelica dahurica 'Hangbaizhi' } \\
\text { (XY pop) }\end{array}$ & $\begin{array}{c}\text { Angelica decursiva } \\
\text { (QY pop) }\end{array}$ \\
AD1 & $114-120$ & $114-120$ & $/$ \\
AD2 & 117 & $/$ & $80-104$ \\
AD4 & $100-102$ & $96-102$ & 201 \\
AD7 & $131-137$ & $131-143$ & 140 \\
AD8 & 146 & $146-152$ & 99 \\
AD9 & $99-117$ & $99-117$ & $102-114$ \\
AD10 & $116-138$ & $116-132$ & 133 \\
AD11 & 127 & $127-136$ & $91-121$ \\
AD12 & 106 & $/$ & 114 \\
AD14 & $102-120$ & $117-120$ & 142 \\
AD17 & $154-157$ & $154-160$ & $128-134$ \\
AD19 & 125 & $125-128$ & $90-93$ \\
AD22 & 87 & 87 & 133 \\
AD23 & 142 & 142 & $108-111$ \\
AD24 & $111-114$ & $111-126$ & $/$ \\
AD26 & $/$ & $/$ & 132
\end{tabular}

${ }^{\mathrm{a}(" / \prime \prime)}$ indicates failure in cross-species amplification

\section{Discussion}

\section{Methods for development of SSR markers in plant}

During the past decades, many methods of developing SSR markers have arisen, such as, (1) screening SSRs from the genomic DNA library, (2) enriching by magnetic beads, (3) PCR-based isolation of SSR arrays, (4) searching SSRs in GenBank, EBML or DDBJ [18, 19]. The methods were labor-intensive, cost and timeconsuming, as some had to construct genomic DNA library and screen the libraries many times for different SSR sequences and the yield of positive clones was very low; or some had to know the genomic information for designing primers; or had to use sophisticated enzyme restriction technique, or lack information on targeted species in database $[20,21]$.

With the rapid development of sequencing technology during the past decade, next-generation sequencing (NGS) technology has made RNA-seq more effective and reliable [18]. An amount of sequence data can be produced by RNA-seq which will be used to develop novel molecular markers [16]. RNA-Seq is time and labor saving, and so effective and economical that can almost overcome the drawbacks of traditional methods cited above. On the other hand, this method is especially applied for species without a reference genome in molecular markers development [22]. Additionally, high stability among technical replicates makes RNA-Seq data more useful [23]. RNA-seq presently has been applied for EST-SSR development in many plant species, such as Rosa roxburghii [24], Neolitsea sericea [25], Salix [26], Elymus sibiricus [27], Xanthoceras sorbifolia [28], etc. In this study, a total of 11,289 putative SSRs were identified. These large dataset resources would be useful in studies on the genetic diversity, and population genetics of $A$. dahurica. We also hope to use the novel EST-SSR markers as an effective tool for further studies on conservations of $A$. dahruica. Firstly, with the EST-SSR markers, we can evaluate the genetic diversity of $A$. dahurica and cultivars in a large scale and protect their germplasm resources as much as possible. Secondly, combining the genetic information produced by SSRs and ecological data may help finding out the impact factors on the increasing decline of this wild resources and implement effective protection measures of this species and its genetic diversity. We can also evaluate the population genetic structure for determining core collection areas as the protection sites or ranges in future, etc.

\section{Transferability of cross-species amplification}

SSR markers have shown transferability in different species, especially for the closely related species. The degree of transferability relays on the conserved degree of flanked sequences and evolutionary stability of SSR [29]. $\mathrm{Xu}$ and Li used 66 polymorphis loci of Liriodendron tulipifera in the amplification of Liriodendron chinense and Michelia alba [30]. They found transferability rates of 85 
Table 4 Locality and voucher information for the populations of Angelica dahurica, Angelica dahurica cv. 'Hangbaizhi' and Angelica decursiva

\begin{tabular}{lllll}
\hline Species & Voucher no. & Collection locality & Geographic coordinates & Sample sizes \\
\hline Angelica dahurica & $2,017,811-\mathrm{BX}(1 \sim 24)$ & Benxi (BX) & $44^{\circ} 22^{\prime} 47^{\prime \prime} \mathrm{N}$ and $124^{\circ} 57^{\prime} 58^{\prime \prime} \mathrm{E}$ & 24 \\
& $2,017,808-\mathrm{AS}(1 \sim 17)$ & Anshan (AS) & $41^{\circ} 00^{\prime} 55^{\prime \prime} \mathrm{N}$ and $123^{\circ} 08^{\prime} 05^{\prime \prime} \mathrm{E}$ & 17 \\
& $2,017,812-\mathrm{KS}(1 \sim 24)$ & Tonghua (KS) & $42^{\circ} 25^{\prime} 49^{\prime \prime} \mathrm{N}$ and $126^{\circ} 06^{\prime} 36^{\prime \prime} \mathrm{E}$ & 24 \\
& $2,017,826-\mathrm{CD}(1 \sim 24)$ & Chengde (CD) & $40^{\circ} 40^{\prime} 12^{\prime \prime} \mathrm{N}$ and $117^{\circ} 40^{\prime} 12^{\prime \prime} \mathrm{E}$ & 24 \\
& $2,015,830-\mathrm{NZ}(1 \sim 5)$ & Nanjing (NZ) & $32^{\circ} 03^{\prime} 41^{\prime \prime} \mathrm{N}$ and $118^{\circ} 50^{\prime} 27^{\prime \prime} \mathrm{E}$ & 5 \\
Angelica dahurica cv.'Hangbaizhi' & $2,016,813-\mathrm{XY}(1 \sim 5)$ & Xianyang (XY) & $34^{\circ} 20^{\prime} 05^{\prime \prime} \mathrm{N}$ and $108^{\circ} 42^{\prime} 25^{\prime \prime} \mathrm{E}$ & 5 \\
& $2,017,925-\mathrm{QY}(1 \sim 5)$ & Qiangyuan (QY) & $24^{\circ} 33^{\prime} 33^{\prime \prime} \mathrm{N}$ and $112^{\circ} 05^{\prime} 37^{\prime \prime} \mathrm{E}$ & 5 \\
Angelica decursiva & & &
\end{tabular}

and 54\%, respectively. Han et al. randomly screened 10 SSRs for the genus of Salix and Populus. The amplification results suggested 14 SSRs were universal in both genus [31]. Zheng et al. firstly demonstrated the genomic SSRs of Dicotyledons (Genus Gossypium) could be used in Monocotyledons (Musa nana), and they also found the transferability of EST-SSR was much stronger than genomic SSR [32]. All of these studies suggested not only that SSR markers have shown transferability in closely related species, but also in different genus, even different family. Before our study, although the development of a congeneric species (Angelica sinensis) SSRs had been published [13], the authors found these markers failed to amplify or had no polymorphism in Angelica dahurica by pre-experiment. The newly developed EST-SSRs here showed 14 out of 16 polymorphic loci in $A$. dahurica had transferability in cultivars and closely related species ( $A$. decursiva). Based on the transferability, the gained SSR markers would improve the efficiency and reduce the cost in marker development, and increase the number of SSRs in genus Angelica. Especially for the species of genus Angelica with little genomic background information, making use of the SSRs of closely related species for developing SSR markers would be very convenient. In this study, according to the cross-species amplification test, we also found the product size range (131-143 bp) of locus AD7 in A. dahurica (including $A$. dahurica cv."Habaizhi") differentiated with that (201 bp) of $A$. decursiva. Locus AD7 would be a potential diagnostic marker for molecular identification of A. dahurica and $A$. decursiva.

\section{Conclusions}

The newly developed 16 EST-SSRs of A. dahurica, achieved by RNA-Seq data analysis in this study would be potentially useful in further investigating the population genetics and genetic diversity of $A$. dahurica, its cultivars and congeneric species. The diagnostic marker (Locus AD7) would be useful in the application of identification of $A$. dahurica and $A$. decursiva.

\section{Methods}

\section{Plant materials}

We sampled Angelica dahurica (Hoffm.) Benth. et Hook. f. ex Franch. \& Sav. from 4 populations from its natural distribution area throughout the central (Chengde, He bei province) and northeastern part (An shan and Benxi, Liao Ning province; Liuhe, Ji Lin province) of China (Details of sampling information and voucher numbers of specimens were shown in Table 4). Within populations, sampled plants were separated by at least $20 \mathrm{~m}$ to avoid multiple samples from the same clone. In each population, fresh leaves from 17 to 24 individuals were collected and preserved in gel-dried silica until DNA extraction. Totally, 89 individuals were selected to assess polymorphisms of the developed microsatellite markers. Ten specimens of $A$. dahurica cv.'Hangbaizhi' and 5 specimens of Angelica decursiva (Miq.) Franch. et Sav. were used for cross-species amplification (Table 4). A specimen (Voucher no. 2017826-CD-X) was collected from $C D$ population (Chengde, Hebei province of China) and then immediately frozen in liquid nitrogen for RNA extraction. Permissions were not necessary for collecting these samples, as they did not distribute in nature reserves and also this species has not been included in the list of national key protected plants. All specimens above were morphologically identified by associate professor Enwei Tian from School of Traditional Chinese Medicine, Southern Medical University (SMU). The voucher specimens were deposited in the herbarium of SMU (Table 4). Our field study and Experimental research complied with local legislation, national and international guidelines. The authors also complied with the Convention on the Trade in Endangered Species of Wild Fauna and Flora.

\section{RNA/DNA extraction, cDNA library construction and Illumina sequencing}

Specimen (Voucher no. 2017826-CD-X) collected from CD population was used to extract total RNA with a modified CTAB method [33]. For detecting the polymorphisms of isolated microsatellite loci, eighty nine 
specimens were used for genotyping (Table 4). Before that, genomic DNA of these specimens was extracted using a modified CTAB method [34]. The quality and quantity of the exacted RNA/DNA were assessed using a NanoDrop 1000 UV/Vis spectrophotometer (Thermo Scientific, Wilmington, DE, USA) and 1.5\% agarose gel electrophoresis. Illumina TruSeq RNA Sample Preparation Kit (Illumina, San Diego, California, USA) was used for constructing RNA-Seq library. Construction of cDNA library and Illumina sequencing on HiSeq 4000 platform were conducted by TGS (Shenzhen, China).

\section{SSR markers development, PCR amplification and polymorphic loci screening}

The raw data yielded from RNA-Seq was firstly conducted with filtering and quality control using Qiagen CLC Assembly Cell v.4.2.1, and then performed de novo assembly with Trinity v2.4.0 $[35,36]$. In order to mine and identify SSR loci, the MicroSAtellite tool (MISA, v1.0) was conducted to hunt putative microsatellite motifs in gained unigenes [37]. The unigenes were searched for 1-6 nucleotide repeat motifs. Mononucleotide repeats were set to extend at least 10 repeats, dinucleotide repeats extend at least six repeats, and repeats of all other motif lengths extend at least three repeats [38]. From the unigenes, SSR primers were designed using Primer 3 according to the criteria given by Tian et al.: (1) product sizes of the PCR amplification between 80 and $300 \mathrm{bp}$; (2) primer length of 18-25 nucleotides; GC content of 40-55\%; (3) annealing temperature $5{ }^{\circ} \mathrm{C}$ lower than the Tm value $\left(55-65^{\circ} \mathrm{C}\right)[39,40]$. After primer designing, we randomly selected 30 pairs of primers under the condition of having targeted product sizes between 80 and $250 \mathrm{bp}$. Di-, tri-, tetra-, penta-, and hexanucleotide repeat loci have at least 9, 6, 5, 4, 3 repeats, respectively. The primers were synthesized in Invitrogen company (Shanghai, China).

Subsequently, these 30 primer pairs were tested for proper PCR amplification in A. dahurica using total genomic DNA (Five samples from each population were tested for PCR). The amplification reactions were carried out with 2720 thermal cycler (Applied Biosystems, Foster City, CA) in $20 \mu \mathrm{l}$ volume containing $20 \mathrm{ng}$ of genomic DNA, $0.2 \mathrm{mM}$ of each dNTP, $0.4 \mu \mathrm{M}$ of each primer, $10 \times$ PCR buffer $\left(\mathrm{Mg}^{2+}\right.$ free), $2.5 \mathrm{mM} \mathrm{Mg} \mathrm{Mg}^{2+}, 1$ unit of Taq DNA polymerase (Takara, Dalian, China) with the following conditions: initial denaturation at $95^{\circ} \mathrm{C}$ for $5 \mathrm{~min}$, followed by 35 cycles of $94^{\circ} \mathrm{C}, 30 \mathrm{~s} ; 50$ to $55^{\circ} \mathrm{C}, 60 \mathrm{~s} ; 72^{\circ} \mathrm{C}, 45 \mathrm{~s}$ and a final extension of $72^{\circ} \mathrm{C}$ for $8 \mathrm{~min}$. The PCR products were visualized at $1.2 \%$ agarose gel electrophoresis. Primers that successfully amplified were then selected for assessing polymorphisms. Before that, the primer pairs were labeled with fluorescent dyes (TAMRA or FAM) at forward primers
( $5^{\prime}$ end). To characterize the genetic polymorphism of these microsatellite markers, genomic DNA of the $89 \mathrm{~A}$. dahurica individuals from the four natural populations were used. PCR reactions and cycling conditions were performed as above. The fragment sizes of the PCR products were determined on the ABI PRISM 3100 Genetic Analyser (Applied Biosystems, Foster City, CA) using Genotyper 4.0 and LIZ 500 (Applied Biosystems, Foster City, CA) as an internal size standard.

\section{SSR markers data analysis}

Possible null alleles, large allelic dropout and genotyping errors in the microsatellite loci were detected with Micro-Checker version 2.2.3 [41]. The diversity indexes, which include the number of alleles $(\mathrm{Na})$, observed $(\mathrm{Ho})$ and expected heterozygosities $(\mathrm{He})$ per locus and population were estimated using GENALEX version 6.1 [42]. We conducted the test for departures from HardyWeinberg equilibrium of the SSR loci using the Markov chain method (settings: dememorization: 1000; batches: 100; iterations per batch: 1000) in Genepop 4.0 [43]. Tests of linkage disequilibrium for every pair of loci across all $A$. dahurica populations were also conducted using GENEPOP 4.0. P-values were adjusted using the Bonferroni correction [44].

\section{Cross-species amplification}

To validate the transferability of the developed SSRs, the polymorphic loci isolated from A. dahurica were tested for amplification in 10 individuals of Angelica dahurica cv. 'Hangbaizhi' and 5 individuals of Angelica decursiva using the same procedures as above, except that the annealing temperature was re-optimized for each locus.

\section{Supplementary information}

Supplementary information accompanies this paper at https://doi.org/10 1186/s12870-020-02374-8.

Additional file $\mathbf{1}$ Table S1. Raw Genotypic data for all individuals of 16 loci.

\section{Abbreviations \\ EST-SSR: Expressed sequence tag-Simple sequence repeat marker; RNA- Seq: RNA sequencing; MISA: MicroSAtellite; HWE: Hardy-Weinberg equilibrium; NGS: Next-generation sequencing; \\ CTAB: Cetyltriethylammnonium bromide; Na: Number of alleles; \\ Ho: Observed heterozygosities; He: Expected heterozygosities}

\section{Acknowledgements}

Not applicable.

\section{Authors' contributions}

$\mathrm{QL}, \mathrm{ZC}$ and ET conceived and designed the work; QL, ZL, WH, WC, FL and CL performed the experiment; QL and ET analyzed the data and wrote this manuscript. WC and ZC reviewed this manuscript. All authors read and approved the manuscript. 


\section{Funding}

This work was supported by National Natural Science Foundation of China (Grant NO. 81603226); Science and Technology Planning Project of Guangdong Province, China (Grant NO. 2016A020226029). These funding bodies did not conduct the design of the study and collection, analysis, and interpretation of data and writing the manuscript.

\section{Availability of data and materials}

Raw sequence information are available in National Center for Biotechnology Information (NCBI) Sequence Read Archive (RNA sequence information, SRA: SRP162120 BioProject ID PRJNA490770). Sequence information for the developed EST-SSR primer pairs has been deposited at GenBank (Accession numbers are provided in Table 1). Other datasets supporting the conclusions of this article are included within the article and its additional file.

\section{Ethics approval and consent to participate}

The authors complied with all relevant institutional, national and international guidelines.

\section{Consent for publication}

Not applicable.

\section{Competing interests}

The authors declare that they have no conflict of interest.

\section{Author details}

${ }^{1}$ Affiliated Cancer Hospital \& Institute of Guangzhou Medical University, Guangzhou 510095, China. ${ }^{2}$ School of Traditional Chinese Medicine, Southern Medical University, Guangzhou 515005, China. ${ }^{3}$ College of Landscape and Ecological Engineering, Hebei University of Engineering, Handan 056038, China.

\section{Received: 11 November 2019 Accepted: 31 March 2020} Published online: 08 April 2020

\section{References}

1. Ge SP. Shennong bencaojing. Collections of ancient herbal essence series (eight). Shanghai: Shanghai University of Traditional Chinese Medicine press; 1992. p. 3-57.

2. Chinese Pharmacopeia Commission. Pharmacopoeia of the People's Republic of China. Bejing: China Med Sci Press; 2015.

3. Guo DD. Investigation and evaluation of the germplasm resources of Radix Angelicae dahuricae. Dissertation. Chengdu: Chengdu University of Traditional Chinese Medicine; 2008

4. Guo DD, Ma YY, Tang L, Chen YZ, Lu Q. Genetic diversity of Radix Angelicae Dahuricae germplasmic resource based on ISSR analysis. Chin Tradit Herbal Drugs. 2009:40:1627-30.

5. Zhao DY, Hao QX, Jin Y, Kang LP, Liu Y, Guo LP. Research advance on the biological characteristics and cultivation technologies of Angelica dahurica. Mod Chin Med. 2015;17:1188-92.

6. Lefèvre F. Human impacts on forest genetic resources in the temperate zone: an updated review. Forest Ecol Manag. 2004;197:257-71.

7. Taheri S, Abdullah TL, Ahmad Z, Abdullah NAP. Effect of acute gamma irradiation on Curcuma alismatifolia varieties and detection of DNA polymorphism through SSR marker. Biomed Res Int. 2014;2014:245-56.

8. Adams SM, Lindmeier JB, Duvernell DD. Microsatellite analysis of the phylogeography, Pleistocene history and secondary contact hypotheses for the killifish, Fundulus heteroclitus. Mol Ecol. 2006;15:1109-23.

9. Rodriquez F, Perez T, Hammer SE, Albornoz J, Dominguez A. Integrating phylogeographic patterns of microsatellite and mtDNA divergence to infer the evolutionary history of chamois (genus Rupicapra). BMC Evol Biol. 2010; 10:222.

10. Wang H, Chen NF, Zheng JY, Wang WC, Pei YY, Zhu GP. Isolation and characterization of eleven polymorphic microsatellite loci for the valuable medicinal plant Dendrobium huoshanense and cross-species amplification. Int J Mol Sci. 2012;13:16779-84

11. Hsu TW, Shih HC, Kuo CC, Chiang TY, Chiang YC. Characterization of 42 microsatellite markers from poison ivy, Toxicodendron radicans (Anacardiaceae). Int J Mol Sci. 2013;14:20414-26.

12. Zhang W, Yuan Q, Jiang D, Zhang Y, Huang L. Development and characterisation of microsatellite markers for the medicinal plant
Scutellaria baicalensis (Lamiaceae). Biochem Syst Ecol. 2014:54:267-71.

13. Lu YY, Cheng T, Zhu TT, Jiang D, Zhou SL, Jin L, Yuan QJ, Huang LQ. Isolation and characterization of 18 polymorphic microsatellite markers for the "female ginseng" Angelica sinensis (Apiaceae) and cross-species amplification. Biochem Systemat Ecol. 2015;61:488-92.

14. Shendure J, Ji H. Next-generation DNA sequencing. Nat Biotechnol. 2008;26: 1135-45.

15. Stapley J, Reger J, Feulner PG, Smadja C, Galindo J, Ekblom R, Bennison C, Ball AD, Beckerman AP, Slate J. Adaptation genomics: the next generation. Trends Ecol Evol. 2010;25:705-12.

16. Ekblom R, Galindo J. Applications of next generation sequencing in molecular ecology of non-model organisms. Heredity. 2011;107:1-15.

17. Duan X, Wang K, Su S, Tian R, Li Y, Chen M. De Novo transcriptome analysis and microsatellite marker development for population genetic study of a serious insect pest, Rhopalosiphum padi (L.) (Hemiptera: Aphididae). PLoS One. 2017;12:e0172513.

18. Taheri S, Abdullah TL, Yusop MR, Hanafi MM, Sahebi M, Azizi P, Shamshiri RR. Mining and development of novel SSR markers using next generation sequencing (NGS) data in plants. Molecules. 2018;23:399.

19. Billotte N, Lagoda PJL, Risterucci AM, Baurens FC. Microsatellite-enriched libraries: applied methodology for the development of SSR markers in tropical crops. Fruits. 1999:54:277-88.

20. Zane L, Bargelloni L, Patarnello T. Strategies for microsatellite isolation: a review. Mol Ecol. 2002;11:1-16.

21. Cost-effective, species-specific microsatellite development for the endangered dwarf bulrush (Typha minima) using next-generation sequencing technology. J Hered. 2010;101:789-93.

22. Garg R, Patel RK, Tyagi AK, Jain M. De novo assembly of chickpea transcriptome using short reads for gene discovery and marker identification. DNA Res. 2011:18:53-63.

23. Zhang J, Liang S, Duan J, Wang J, Chen S, Cheng Z, Zhang Q, Liang X, Li Y. De novo assembly and Characterization of the Transcriptome during seed development, and generation of genic-SSR markers in Peanut (Arachis hypogaea L.). BMC Genome. 2012;13:90.

24. Yan $X Q$, Lu M, An HM. Analysis on SSR information in trancriptome and development of molecular markers in Rosa roxburghii. Acta Horticulturae Sinica. 2015;42:341-9.

25. Chen LY, Cao YN, Yuan N, Nakamura K, Wang GM, Qiu YX. Characterization of transcriptome and development of novel EST-SSR makers based on nextgeneration sequencing technology in Neolitsea sericea (Lauraceae) endemic to east Asian land-bridge islands. Mol Breeding. 2015;35:1-15.

26. Jia H, Yang H, Sun P, Li J, Zhang J, Guo Y, Han X, Zhang G, Lu M, Hu J. De novo transcriptome assembly, development of EST-SSR markers and population genetic analyses for the desert biomass willow, Salix psammophila. Sci Rep. 2016:6:39591.

27. Zhou Q, Luo D, Ma L, Xie W, Wang Y, Wang Y, Liu Z. Development and cross-species transferability of EST-SSR markers in Siberian wildrye (Elymus sibiricus L.) using Illumina sequencing. Sci Rep. 2016;6:20549.

28. Liu YL, Li W, Dong SB, Mu XY, Zhang ZX. Transcriptome analysis of Xanthoceras sorbifolia and development of EST-SSR markers. J Northwest A \& F University. 2017;45:89-95

29. Cheng XM, Huang XX. Development and application of SSR markers in plants. Chin Agr Sci Bull. 2011;27:304-7.

30. Xu M, Li HG. Development and characterization of microsatellite markers from expressed sequence tags for Liriodendron. Mol Plant Breeding. 2008; 28:615-8.

31. Han J, Wang H, Wang JM, Zhao JR, Yang MS. Genetic diversity analysis of Salicaceae cultivars by transferability of SSR primers. Mol Plant Breeding. 2009:7:904-11.

32. Zheng LS, Shi YZ, Wang JY, Huang BZ, Ji XR, Zhang BC, Yuan YL, Wu LT. Transferability of cotton EST- SSRs markers to Musa. Chin Agr Sci Bull. 2008:24:33-7.

33. Chang S, Puryear J, Cairney J. A simple and efficient method for isolating RNA from pine trees. Plant Mol Biol Rep. 1993:11:113-6.

34. Yang JB, Li DZ, Li HT. Highly effective sequencing whole chloroplast genomes of angiosperms by nine novel universal primer pairs. Mol Ecol Resour. 2014;14:1024-31.

35. Grabherr MG, Haas BJ, Yassour M, Levin JZ, Thompson DA, Amit I, Adiconis X, Fan L, Raychowdhury R, Zeng Q. Trinity: reconstructing a full-length 
transcriptome without a genome from RNA-Seq data. Nat Biotechnol. 2011; 29:644.

36. Grabherr MG, Haas BJ, Yassour M, Levin JZ, Thompson DA, Amit I, Adiconis X, Fan L, Raychowdhury R, Zeng Q. Full-length transcriptome assembly from RNA-Seq data without a reference genome. Nat Biotechnol. 2011;29:644-52.

37. Beier S, Thiel T, Münch T, Scholz U, Mascher M. MISA-web: a web server for microsatellite prediction. Bioinformatics. 2017;33:2583-5.

38. Zheng LN, Nason JD, Liang D, Ge XJ, Yu H. Development and characterization of microsatellite loci for Ficus hirta (Moraceae). Appl Plant Sci. 2015:3:1500034.

39. Rozen S, Skaletsky H. Primer3 on the WWW for general users and for biologist programmers. In: Bioinformatics Methods and Protocols, second ed. Berlin: Springer; 1999. p. 365-86.

40. Tian EW, Yu H, Zhang DY, Nason JD. Development ofmicrosatellite loci for Blastophaga javana (Agaonidae), the pollinating wasp of Ficus hirta (Moraceae). Am J Bot. 2011:98:e41-3.

41. Van Oosterhout C, Hutchinson WF, Wills DP, Shipley P. MICRO-CHECKER: software for identifying and correcting genotyping errors in microsatellite data. Mol Ecol Notes. 2004;4:535-8.

42. Peakall R, Smouse PE. GENALEX 6: genetic analysis in excel. Population genetic software for teaching and research. Mol Ecol Notes. 2006;6:288-95.

43. Raymond M, Rousset F. Genepop (version 1.2): population genetics software for exact tests and ecumenicism. J Hered. 1995;86:248-9.

44. Rice WR. Analyzing tables of statistical tests. Evolution. 1989;43:223-5.

\section{Publisher's Note}

Springer Nature remains neutral with regard to jurisdictional claims in published maps and institutional affiliations.

- fast, convenient online submission

- thorough peer review by experienced researchers in your field

- rapid publication on acceptance

- support for research data, including large and complex data types

- gold Open Access which fosters wider collaboration and increased citations

- maximum visibility for your research: over $100 \mathrm{M}$ website views per year

At $\mathrm{BMC}$, research is always in progress.

Learn more biomedcentral.com/submissions 